\title{
In vivo Evaluation of Human Embryonic Stem Cells Isolated by 57-C11 Monoclonal Antibody
}

\author{
Won-Tae Kim*, Hyun Min Lee*, Min Kyu Kim, Hong Seo Choi, Chun Jeih Ryu \\ Institute of Anticancer Medicine Development, Department of Integrative Bioscience and Biotechnology, Sejong University, Seoul, Korea
}

Background: The normal cells derived from human embryonic stem cells (hESCs) are regarded as substitutes for damaged or dysfunctional adult cells. However, tumorigenicity of hESCs remains a major challenge in clinical application of hESC-derived cell transplantation. Previously, we generated monoclonal antibody (MAb) 57-C11 specific to the surface molecule on undifferentiated hESCs. The aim of this study is to prove whether 57-C11-positive hESCs are pluripotent and tumorigenic in immunodeficient mice.

Methods: Undifferentiated hESCs were mixed with retinoic acid (RA)-differentiated hESCs at different ratios prior to 57-C11-mediated separation. To isolate 57-C11-positive hESCs from the mixture, biotinylated 57-C11 and streptavidin-coated magnetic beads were added to the mixture. Unbound 57-C11-negative hESCs were first isolated after applying magnet to the cell mixture, and 57-C11-bound hESCs were then released from the magnetic beads. In order to measure the efficiency of separation, 57-C11-positive or -negative hESCs were counted after isolation. To evaluate the efficiency of teratoma formation in vivo, 57-C11-positive or negative cells were further injected into left and right, respectively, testes of nonobese diabetic/severe combined immunodeficiency (NOD/SCID) mice.

Results: Approximately $77 \sim 100 \%$ of undifferentiated hESCs were isolated after applying 57-C11-coated magnetic beads to the mixed cell populations. Importantly, teratomas were not observed in NOD/SCID mice after the injection of isolated 57-C11-negative hESCs, whereas teratomas were observed with 57-C11-positive hESCs.

Conclusion: 57-C11-positive hESCs are pluripotent and tumorigenic. The combination of 57-C11 and magnetic beads will be useful to eliminate remaining undifferentiated hESCs for the safe cell transplantation.

Keywords: Human embryonic stem cells, Surface marker, 57-C11, Magnetic beads, Teratoma

Accepted for publication October 26, 2016, Published online November 30,2016

Correspondence to Won-Tae Kim

Department of Integrative Bioscience and Biotechnology, Sejong University, Seoul 05006, Korea

Tel: +82-2-3408-3718, Fax: +82-2-3408-4334

E-mail: semidivine@hanmail.net

Co-Correspondence to Chun Jeih Ryu

Department of Integrative Bioscience and Biotechnology, Sejong University, Seoul 05006, Korea

Tel: +82-2-3408-3718, Fax: +82-2-3408-4334

E-mail: cjryu@sejong.ac.kr

*These authors equally contributed to the work.

(a) This is an open-access article distributed under the terms of the Creative Commons Attribution Non-Commercial License (http://creativecommons.org/ licenses/by-nc/4.0/), which permits unrestricted non-commercial use, distribution, and reproduction in any medium, provided the original work is properly cited.

\section{Introduction}

Human embryonic stem cells (hESCs) have been regarded as a potential source of therapeutic cells for many diseases caused by tissue loss or dysfunction (1). Because of the self-renewal and pluripotency of hESCs, however, teratoma formation is a seriously raised concern whenever utilizing hESC-derived differentiated cells $(2,3)$. The number of hESC-derived cell transplantation studies into animal models have been done, but teratoma formation was not detected depending on experimental conditions (4-6). Longer in vitro differentiation of hESCs seems to reduce the risk of teratoma formation due to low survival rate of hESC-derived cells in animal models. However, survived dopaminergic implants in parkinsonian rats ex- 
hibit expanding cores of undifferentiated mitotic neuroepithelial cells, which can be tumorigenic (7). Furthermore, hESC-derived neural precursor cells have repeatedly induced tumors in animal models even though remaining hESCs were not detected $(8,9)$. Thus, the elimination of remaining undifferentiated hESCs is a major hurdle to hESC-derived cell transplantation.

Previously, we generated a panel of MAbs against surface molecules on undifferentiated hESCs (10). One of the MAbs, 57-C11 (IgG1, k), recognizes the phosphorylated form of adenovirus early-1B-55kDa associated protein 5 (E1B-AP5) or heterogeneous nuclear ribonucleoprotein U-like 1 (hnRNPUL1) (11). E1B-AP5 is a member of the heterogeneous nuclear ribonucleoprotein (hnRNP) family and is ubiquitously expressed in the nucleus and cytoplasm in all tissues (12). However, we showed for the first time that 57-C11-reactive E1B-AP5 is expressed on the cell surface of undifferentiated hESCs and cell surface-expressed E1B-AP5 is downregulated upon the differentiation of hESCs, suggesting that cell surface-expressed E1B-AP5 is a specific surface marker for undifferentiated hESCs (11). In this study, we have tested whether 57-C11 is able to eliminate undifferentiated hESCs from the mixture of undifferentiated and differentiated hESCs. To isolate 57-C11-positive hESCs, 57-C11 was biotinylated and added to the mixture of undifferentiated and differentiated hESCs. Sequentially, streptavidin-coated magnetic beads were added into the same tube. After applying magnet to the mixture, 57-C11-positive and negative hESCs were separated and analyzed. The isolated cells were further validated in in vivo animal model by injecting the isolated cells into right and left testes of the same NOD/SCID mice. The results showed that teratoma formation was not detected with 57-C11-negative hESCs whereas teratoma was detected with 57-C11-positve hESCs. The results indicate that 57-C11-positive hESCs are really pluripotent and tumorigenic while 57-C11-negative hESCs are not. The results also suggest that 57-C11-mediated isolation system will be useful for the elimination of residual undifferentiated hESCs from the preparation of hESC-derived differentiated cells.

\section{Materials and Methods}

\section{Cell culture}

H9 hESCs were cultured on irradiated mouse embryonic fibroblast (MEF) as described previously $(13,14)$. hESCs were fed daily with DMEM/F12 medium supplemented with 20\% Knockout serum replacement (Life Technologies, Seoul, Korea), 0.1 mM 2-Mercaptoethanol,
$1 \%$ Non-essential amino acid, $1 \mathrm{mM}$ glutamine, $100 \mathrm{U} / \mathrm{ml}$ penicillin $\mathrm{G}, 100 \mu \mathrm{g} / \mathrm{ml}$ streptomycin, and $4 \mathrm{ng} / \mathrm{ml}$ basic fibroblast growth factor (PeproTech, Rocky Hill, NJ, USA). Feeder-free culture method was performed as described previously $(13,15)$. Briefly, $10 \mu \mathrm{M}$ of $\mathrm{Y} 27632$ (Sigma-Aldrich, Seoul, Korea) were treated for 1 hour prior to detaching hESCs, the cells were harvested with trypsin-EDTA. After elimination of MEF cells on gelatin coated tissue culture dish, hESCs were cultured in conditioned medium supplemented with $10 \mu \mathrm{M}$ of Y27632 on tissue culture dish coated with Matrigel (BD Biosciences, Seoul, Korea). For differentiation of hESCs, cells were treated $10^{-5} \mathrm{M}$ retinoic acids (RA) in culture medium for $10 \sim 14$ days. Colo205 cells were maintained following recommendation of ATCC.

\section{Antibody biotinylation}

Antibody was biotinylated by using DSB- $\mathrm{X}^{\mathrm{TM}}$ biotin labeling kit (Life Technologies) according to manufacturer's procedure.

\section{Isolation of 57-C11-positive and -negative hESCs}

Cell isolation was carried out by using Dynabeads FlowComp Flexi kit (Life Technologies) according to the manufacturer's protocol. The cells were detached with dissociation solution for human ES/iPS cells (ReproCELL). To prevent physiological cell damage, dissociation buffer was immediately neutralized by complete medium. The mixture of undifferentiated and RA-treated hESCs were suspended in $500 \mu 1$ of cold isolation buffer (phosphate buffered saline (PBS), $\mathrm{pH} 7.4,5 \%$ Knockout serum re-

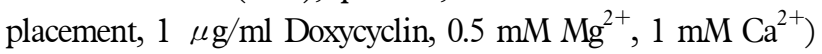
in Eppendorf tube and incubated with $20 \mu \mathrm{g}$ of biotinylated $57-\mathrm{C} 11$ for $30 \mathrm{~min}$ at $4^{\circ} \mathrm{C}$ with rolling and tilting. Cells were harvested after addition of $500 \mu 1$ of cold isolation buffer. Cells $\left(2 \times 10^{6}\right)$ were then resuspended in 500 $\mu 1$ of cold isolation buffer and incubated for $30 \mathrm{~min}$ at $4^{\circ} \mathrm{C}$ with rolling and tilting after addition of $50 \mu 1\left(7.5 \times 10^{7}\right.$ beads) of Dynabeads (Life Technologies). 57-C11-positive hESCs were collected by placing the tube in a magnet for 2 3 min. The supernatant containing 57-C11-negative hESCs was carefully removed in the magnet, and the bead/cell complexes were cleaned up by a total of three washes. Cells were then removed from the magnet by incubation of $1 \mathrm{ml}$ of FlowComp Release Buffer (Life Technologies) for $10 \mathrm{~min}$ at room temperature (RT) with rolling and tilting. The supernatant with 57-C11-positive hESCs was carefully transferred to a new tube and put on the magnet again to remove residual beads. The supernatant with 57-C11-positive hESCs was subjected to cen- 
trifugation at $600 \mathrm{x}$ g for $10 \mathrm{~min}$, and the bead free-cells were resuspended by stepwise addition of a 1:300 mixture of PBS: Matrigel (BD Bioscience) to a final total volume of $50 \mu 1$ before injection.

\section{Teratoma formation}

The procedure of teratoma formation experiments was performed as described (16). All procedures were carried out under guidelines approved by the Institutional Review Board (SJU-2015-008) and Institutional Animal Care and Use Committee (IACUC No. SJ-20140801) of Sejong University. Male NOD/SCID mice ( $8 \sim 12$ weeks) were used for all experiments. All procedures were carried out in a biological safety cabinet under sterile conditions using sterile materials. Injection of hESCs into testes was done under anesthesia. Mice received the following anesthetics and analgesics: Zoletil $50(30 \mathrm{mg} / \mathrm{kg}) /$ Rompun $(9.32 \mathrm{mg} / \mathrm{kg})$. For testis injection, a sterile $1 \mathrm{ml}$ syringe with a $31 \mathrm{G}$ needle was injected into testes with hESC suspension $(50 \mu \mathrm{l})$. After successful injection, the needle was retracted swiftly, the injection site was pressed with a cotton swab for about $1 \mathrm{~min}$, and then a sterile, resorbable wound pad was placed at the injection site. Teratomas were surgically removed at $12 \sim 18$ weeks postinjection under sterile conditions. The sizes of teratomas were measured by a ruler.

\section{Flow cytometric analysis}

Flow cytometry analysis was performed described as previous study (10). Briefly, the undifferentiated H9, RA-induced differentiated H9 cells or Colo205 cells were incubated with $20 \mu \mathrm{g}$ of DSB-X biotin-labeled 57-C11. After isolation process described above, the cells were washed with PBS ( $\mathrm{pH} 7.4)$ supplemented with $1 \%$ bovine serum albumin (PBA). The cells were incubated with 57-C11 or biotin-labeled 57-C11 for $30 \mathrm{~min}$, followed by fluorescein isothiocyanate-conjugated anti-mIgG or streptavidin-phycoerythrin, depending on the isotypes of the primary antibodies. After washing with PBA, Propidium iodide-negative cells were analyzed by FACScalibur (BD biosciences).

\section{Results}

\section{Biotinylation and characterization of $57-\mathrm{Cll}$}

Previously, we found that 57-C11-reactive E1B-AP5 is closely associated with pluripotent and undifferentiated H9 hESCs and the surface expression of 57-C11-reactive E1B-AP5 is downregulated during the differentiation of H9 cells (11). To test whether 57-C11 is able to specifically
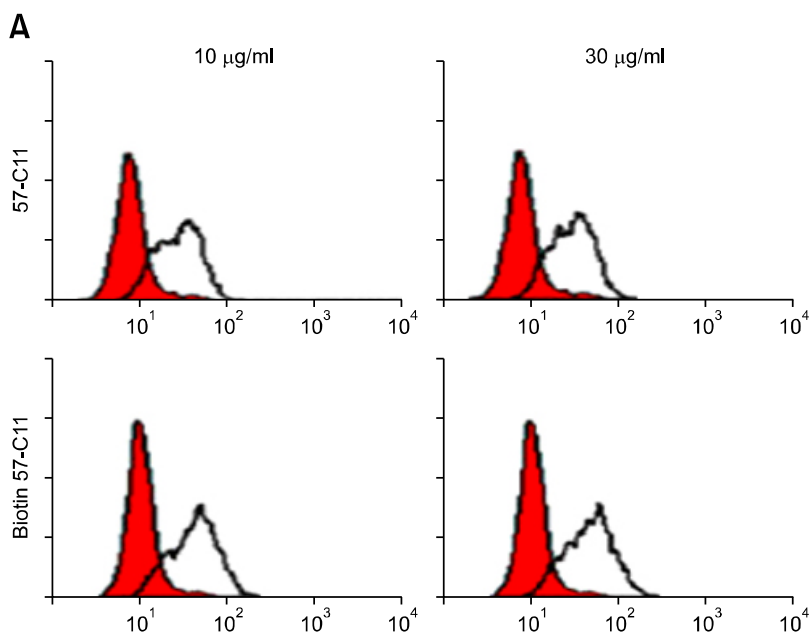

B


C

\begin{tabular}{|l|c|c|c|c|c|}
\hline Undiff-H9 $\left(\times 10^{4}\right)$ & 0 & 1 & 3 & 5 & 10 \\
\hline RA-H9 $\left(\times 10^{4}\right)$ & 10 & 9 & 7 & 5 & 0 \\
\hline $57(+) \mathrm{H} 9\left(\times 10^{4}\right)$ & $1.08 \pm 0.19$ & $2.08 \pm 0.14$ & $3.88 \pm 0.13$ & $4.92 \pm 0.26$ & $10.13 \pm 0.57$ \\
\hline $57(-) \mathrm{H} 9\left(\times 10^{4}\right)$ & $8.21 \pm 0.19$ & $6.29 \pm 0.40$ & $4.33 \pm 0.31$ & $3.29 \pm 0.14$ & $1.42 \pm 0.19$ \\
\hline $\begin{array}{l}\text { Recovery rate of } \\
\text { undiff-H9 }(\%)\end{array}$ & & 100 & 93.3 & 76.8 & 90.5 \\
\hline
\end{tabular}

Fig. 1. Characterization of biotinlyated 57-C11 antibody. (A) Biotinylation efficiency of 57-C11 was tested by flow cytometry analysis. H9 cells were reacted with 10 and $30 \mu \mathrm{g} / \mathrm{ml}$ of unbiotinylated or biotinylated 57-C11. The binding of antibody was measured with FITC-conjugated anti-mlgG or PE-conjugated streptavidin. (B) Flow cytometry analysis of H9 cells with 57-C11. After isolation with $20 \mu \mathrm{g} / \mathrm{ml}$ of biotinylated $57-\mathrm{C} 11$ or CA142 from the mixed cells, the surface binding for 57-C11 was confirmed in 57-C11-positive/negative and CA142-positive/negative cells, respectively. (C) Recovery rate of undifferentiated H9 cells after isolation with 57-C11. Undifferentiated and RA-differentiated H9 cells were mixed at different ratios and undifferentiated $\mathrm{H} 9$ cells were recovered with 57-C11-mediated isolation procedure. The 57-C11-mediated isolation procedure nonspecifically recovered approximately $10 \%$ cells $\left(1.08 \times 10^{4}\right.$ cells $)$ from $10 \times 10^{4}$ RA-differentiated $\mathrm{H} 9$ cells. Therefore, the number was subtracted from all the numbers of recovered cells in the calculation of the recovery rate. 
eliminate undifferentiated H9 cells from the mixture of undifferentiated and differentiated $\mathrm{H} 9$ cell population, in this study, we have developed a 57-C11-mediated magnetic cell separation system, based on the specificity of 57-C11 to undifferentiated H9 cells (11). First, 57-C11 was biotinylated and 57-C11-bound H9 cells were analyzed by flow cytometry analysis with streptavidin-phycoerythrin conjugate. As shown in Fig. 1A, H9 cells ( $10^{6}$ cells) were readily detected with biotin-labeled 57-C11 at final concentrations of 10 or $30 \mu \mathrm{g} / \mathrm{ml}$. As compared with that of $10 \mu \mathrm{g} / \mathrm{ml}$ of biotin-labeled 57-C11, 57-C11 binding to $\mathrm{H} 9$ cells were not significantly increased with $30 \mu \mathrm{g} / \mathrm{ml}$ of biotin-labeled 57-C11, indicating that $10 \mu \mathrm{g} / \mathrm{ml}$ of biotin-labeled 57-C11 is enough to analyze one million hESCs. To confirm whether biotin-labeled 57-C11/streptavidin-magnetic beads were able to specifically isolate undifferentiated H9 cells from the mixed cell population, CA142 (IgG1, k), a MAb specific to surface antigen on Mycoplasma hyorhinis, was also biotinylated and used as a control isotype antibody (17). When the mixture of undifferentiated H9 hESCs and Colo205 cells were incubated

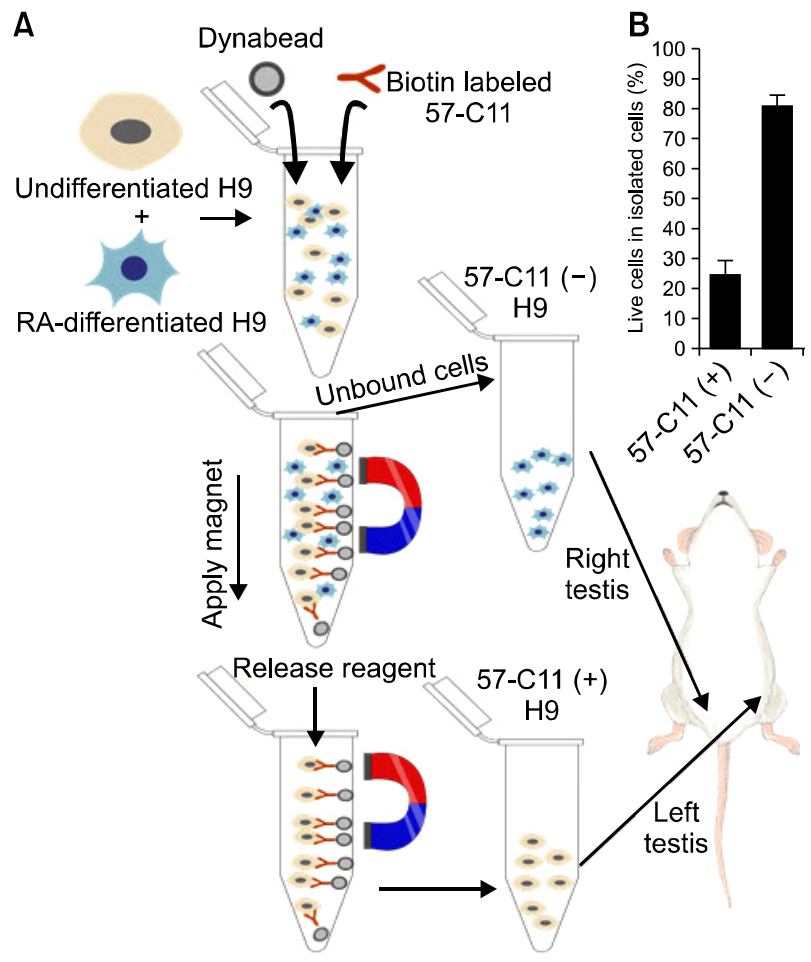

Fig. 2. Strategy of isolation of undifferentiated hESCs with 57-C11. (A) The model of isolation process with biotinylated 57-C11 using Dynabeads. (B) The live cells were counted after the isolation with 57-C11 from the mixture of undifferentiated and RA-induced differentiated H9 cells. The percentage of live cells was estimated by flow cytometry analysis using Pl-negative cell population. with 10 or $20 \mu \mathrm{g} / \mathrm{ml}$ of biotin-labeled 57-C11 and subjected to the streptavidin-magnetic beads-associated isolation procedure, 57-C11-positive H9 cells were clearly separated with $20 \mu \mathrm{g} / \mathrm{ml}$ of biotin-labeled 57-C11 (data not shown). To reflect the possible scenario of contaminating hESC in mixed cell populations, the mixture of undifferentiated and differentiated hESCs were incubated with $20 \mu \mathrm{g} / \mathrm{ml}$ of biotin-labeled 57-C11 and subjected to the same isolation procedure (Fig. 2A). 57-C11-positive undifferentiated H9 cells were mostly removed with 20 $\mu \mathrm{g} / \mathrm{ml}$ of biotin-labeled $57-\mathrm{C} 11$ while the same H9 cells were not removed with the irrelevant antibody CA142 (data not shown and Fig. 1B). Thus, it seems that $57-\mathrm{C} 11 /$ streptavidin beads is able to specifically isolate 57-C11-positive undifferentiated hESCs from the mixed cell population.

\section{Evaluation of separation efficiency of 57-C11-positive hESCs}

To examine the applicability and efficiency of this separation strategy, we prepared several pools of undifferentiated and differentiated $\mathrm{H} 9$ cells at different ratios $(0,10,30,50$, or $100 \%$ undifferentiated H9 hESCs) and performed the same 57-C11-mediated isolation procedure (Fig. 2A). Approximately $10 \%$ of hESCs were recovered from $1 \times 10^{5}$ cells of differentiated H9 cells after the isolation procedure, suggesting that some cells are isolated from the differentiated $\mathrm{H} 9$ cells during the isolation procedure (Fig. 1C). Approximately $91 \%$ of hESCs were recovered from $1 \times 10^{5}$ cells of undifferentiated H9 cells after the isolation procedure (Fig. 1C). Our previous studies showed that approximately $89 \sim 96 \%$ of undifferentiated H9 cells were 57-C11-positive (11). Therefore, it seems that undifferentiated hESCs are almost completely recovered through the isolation procedure. When undifferentiated and differentiated hESCs were mixed at different ratios, approximately $77 \sim 100 \%$ of undifferentiated H9 hESCs were recovered after the isolation procedure (Fig. 1C). Thus, the spiking experiments suggest that the recovery rate of 57-C11-positive hESCs from mixed cell populations is approximately $77 \sim 100 \%$.

\section{Teratoma formation of $57-\mathrm{Cll}$ positive hESCs in NOD/SCID mice}

Before we validated whether isolated 57-C11-positive H9 cells were tumorigenic in NOD/SCID mice, we tested how many undifferentiated hESCs were able to form teratomas in NOD/SCID mice. Undifferentiated hESCs rapidly undergo apoptosis after the preparation of single cell suspensions from the colonies. Therefore, more than one 


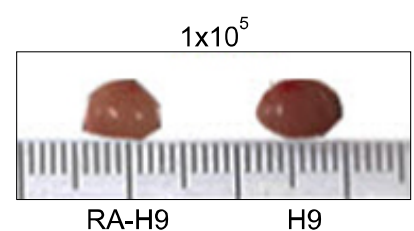

$4 \times 10^{5}$



H9
$1 \times 10^{6}$

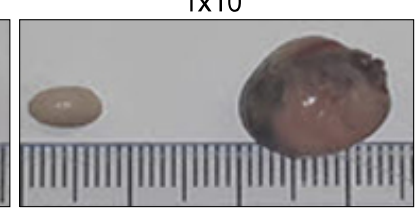

$\mathrm{H} 9$

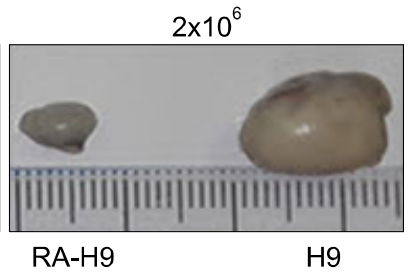

Fig. 3. Teratoma formation of $\mathrm{H} 9$ cells. $0.1,0.4,1$, and $2 \times 10^{6}$ of undifferentiated $\mathrm{H} 9$ or RA-induced differentiated H9 cells were injected into the right or left testis of NOD/SICD mice, respectively. The teratomas were recovered $8 \sim 18$ weeks after injection. million hESCs are recommended to use for teratoma formation in immunodeficient mice $(16,18)$. When we injected with $1 \times 10^{5}, 4 \times 10^{5}, 1 \times 10^{6}$, or $2 \times 10^{6}$ cells of undifferentiated and RA-differentiated $\mathrm{H} 9$ cells into the left and right testes of the same mice, respectively, we found that undifferentiated $\mathrm{H} 9$ cells could form teratomas with $4 \times 10^{5}$ cells under our experimental condition $8 \sim 18$ weeks after injections while RA-differentiated H9 cells were not able to do (Fig. 3).

The overall scheme of the experiment including magnetic cell separation of 57-C11-positive and -negative H9 hESCs from mixed cell populations and teratoma formation of isolated $\mathrm{H} 9 \mathrm{hESCs}$ in NOD/SCID mice is shown in Fig. 2A. Before the injection of 57-C11-positive and -negative hESCs into NOD/SCID mice, the viability of isolated $\mathrm{H} 9$ cells were tested. After the isolation procedure, approximately $85 \%$ of 57-C11-negative cells remained alive while only $25 \%$ of $57-\mathrm{C} 11$ positive cells remained alive (Fig. 2B). It seems that the releasing processes from magnetic beads are harmful to 57-C11-positive H9 cells. Therefore, the viability of injected hESCs were checked before injection and $1 \times 10^{6}$ cells of 57-C11-positive and negative hESCs were injected into left and right testes of NOD/SCID mice. Untreated and RA-differentiated H9 cells were also injected into NOD/SCID mice as a control experiment in the same way. When the first set of mice were opened at 12 weeks postinjection, teratoma formation was not observed even with untreated H9 cells (Fig. 4A). When the second set of mice were opened at 18 weeks postinjection, teratoma formation was observed with 57-C11-positive H9 cells or untreated H9 cells whereas it was not observed with 57-C11-negative H9 cells or RA-treated H9 cells (Fig. 4A and 4B). The results suggest that 57-C11-positive hESCs are undifferentiated and pluripotent hESCs whereas 57-C11-negative hESCs are not.
A

\begin{tabular}{|c|c|c|c|c|}
\hline & \multicolumn{2}{|c|}{ H9 } & \multicolumn{2}{c|}{ Biotin-57-C11 } \\
\hline Testis & Right & Left & Right & Left \\
\hline Injected cells & RA-H9 & H9 & $57-C 11(-)$ & $57-C 11(+)$ \\
\hline $\begin{array}{c}\text { Teratoma } \\
(12 \text { weeks })\end{array}$ & $\mathrm{X}$ & $\mathrm{X}$ & $\mathrm{X}$ & $\mathrm{X}$ \\
\hline $\begin{array}{c}\text { Teratoma } \\
\text { (18 weeks) }\end{array}$ & $\mathrm{X}$ & $\mathrm{O}$ & $\mathrm{X}$ & $\mathrm{O}$ \\
\hline
\end{tabular}

B

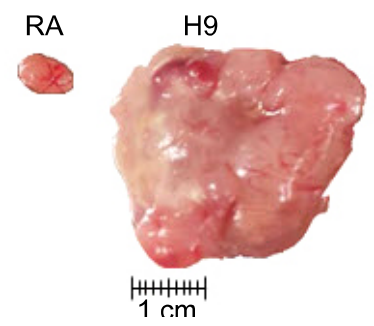

$57-\mathrm{C} 11(-) \quad 57-\mathrm{C} 11(+)$

Fig. 4. Teratoma formation of 57-C11-positive cells. (A) Table of teratoma formation of 57-C11-positive cells at 12 or 18 weeks after injection. (B) After the isolation of 57-C11 positive cells from the mixture of undifferentiated and RA-induced differentiated $\mathrm{H} 9$ cells, the $1 \times 10^{6}$ cells of $57-C 11$-positive or -negative cells were injected into the left or right testis of NOD/SCID mice. The teratomas were recovered 18 weeks postinjection and measured size and weight before fixation. The undifferentiated $\mathrm{H} 9(\mathrm{H} 9)$ and RA-induced differentiated H9 (RA) cells were used as positive and negative controls, respectively.

\section{Discussion}

Previously, we generated the MAb 57-C11 that recognizes the phosphorylated form of E1B-AP5 on the surface of undifferentiated hESCs $(10,11)$. Further studies revealed that the expression of 57-C11-reactive E1B-AP5 has a close relationship with pluripotent marker expression and is downregulated during the differentiation of hESCs (11), suggesting that 57-C11-reactive E1B-AP5 will be a specific surface marker for undifferentiated hESCs. To prove whether 57-C11-reactive E1B-AP5 is a specific sur- 
face marker for undifferentiated hESCs in vivo, we isolated 57-C11-positive and -negative hESCs by magnetic separation system and tested the capacity of teratoma formation in NOD/SCID mice. The results showed that 57-C11-positive hESCs had capacity to form teratoma whereas 57-C11-negative hESCs had not, suggesting that 57-C11-positve hESCs are really pluripotent and tumorigenic. The result also suggests that 57-C11 would be a good tool to separate remaining undifferentiated hESCs from the mixed cell population.

In the first set of injection into $2 \mathrm{NOD} / \mathrm{SCID}$ mice, teratoma formation was not observed even with untreated $\mathrm{H} 9$ cells at 12 weeks postinjection (Fig. 4A). To generate consistent teratomas in immunodeficient mice, many researchers have injected more than one million undifferentiated hESCs. Generally, hESCs rapidly undergo apoptosis after the preparation of single cell suspensions from the colonies even with Y-27632, the selective inhibitor of Rho-associated, coiled-coil containing protein kinase (19). Therefore, we assumed that although injected cells were alive, they were damaged and were not healthy enough to form teratomas at 12 weeks postinjection. In the second set of injection with the same cell preparation, therefore, the hESCs were given more time to recover from the damage. At 18 weeks postinjection, teratomas were observed in both untreated $\mathrm{H} 9$ and 57-C11-positive H9 cells. However, the teratoma size of 57-C11-positive hESCs were still smaller than that of untreated hESCs (Fig. 4B). In the first step of the isolation of 57-C11-positive hESCs, 57-C11-positive hESCs were readily separated by streptavidin-magnetic beads from mixed hESC population. After further separation of 57-C11-positive hESCs from magnetic beads, however, only $25 \%$ of isolated 57-C11-positive hESCs remained alive (Fig. 3B). Therefore, it is tempting to speculate that 57-C11-positive hESCs suffer from cytotoxic damage during the releasing processes from magnetic beads. More investigation needs to safely separate captured hESCs from magnetic beads.

\section{Acknowledgments}

This study was supported in part by the National Research Foundation of Korea (2016918220, 2016008610, and 2016903249). We thank Saerom Lee for helping us illustrate graphic strategy.

\section{Potential conflict of interest}

The authors have no conflicting financial interest.

\section{References}

1. Thomson JA, Itskovitz-Eldor J, Shapiro SS, Waknitz MA, Swiergiel JJ, Marshall VS, Jones JM. Embryonic stem cell lines derived from human blastocysts. Science 1998;282: $1145-1147$

2. Vogel G. Cell biology. Ready or not? Human ES cells head toward the clinic. Science 2005;308:1534-1538

3. Hentze H, Graichen R, Colman A. Cell therapy and the safety of embryonic stem cell-derived grafts. Trends Biotechnol 2007;25:24-32

4. Zhang SC, Wernig M, Duncan ID, Brüstle O, Thomson JA. In vitro differentiation of transplantable neural precursors from human embryonic stem cells. Nat Biotechnol 2001; 19:1129-1133

5. Laflamme MA, Gold J, Xu C, Hassanipour M, Rosler E, Police S, Muskheli V, Murry CE. Formation of human myocardium in the rat heart from human embryonic stem cells. Am J Pathol 2005;167:663-671

6. Brederlau A, Correia AS, Anisimov SV, Elmi M, Paul G, Roybon L, Morizane A, Bergquist F, Riebe I, Nannmark U, Carta M, Hanse E, Takahashi J, Sasai Y, Funa K, Brundin P, Eriksson PS, Li JY. Transplantation of human embryonic stem cell-derived cells to a rat model of Parkinson's disease: effect of in vitro differentiation on graft survival and teratoma formation. Stem Cells 2006; 24:1433-1440

7. Roy NS, Cleren C, Singh SK, Yang L, Beal MF, Goldman SA. Functional engraftment of human ES cell-derived dopaminergic neurons enriched by coculture with telomerase-immortalized midbrain astrocytes. Nat Med 2006; 12:1259-1268

8. Doi D, Morizane A, Kikuchi T, Onoe H, Hayashi T, Kawasaki T, Motono M, Sasai Y, Saiki H, Gomi M, Yoshikawa T, Hayashi H, Shinoyama M, Refaat MM, Suemori H, Miyamoto S, Takahashi J. Prolonged maturation culture favors a reduction in the tumorigenicity and the dopaminergic function of human ESC-derived neural cells in a primate model of Parkinson's disease. Stem Cells 2012;30:935-945

9. Seminatore C, Polentes J, Ellman D, Kozubenko N, Itier V, Tine S, Tritschler L, Brenot M, Guidou E, Blondeau J, Lhuillier M, Bugi A, Aubry L, Jendelova P, Sykova E, Perrier AL, Finsen B, Onteniente B. The postischemic environment differentially impacts teratoma or tumor formation after transplantation of human embryonic stem cell-derived neural progenitors. Stroke 2010;41:153-159

10. Choi HS, Kim H, Won A, Kim JJ, Son CY, Kim KS, Ko JH, Lee MY, Kim CH, Ryu CJ. Development of a decoy immunization strategy to identify cell-surface molecules expressed on undifferentiated human embryonic stem cells. Cell Tissue Res 2008;333:197-206

11. Choi HS, Kim WT, Kim H, Kim JJ, Ko JY, Lee SW, Jang YJ, Kim SJ, Lee MJ, Jung HS, Kzhyshkowska J, Um SJ, Lee MY, Lee SH, Kim CH, Ryu CJ. Identification and characterization of adenovirus early region 1B-associated 
protein 5 as a surface marker on undifferentiated human embryonic stem cells. Stem Cells Dev 2011;20:609-620

12. Gabler S, Schütt H, Groitl P, Wolf H, Shenk T, Dobner T. E1B 55-kilodalton-associated protein: a cellular protein with RNA-binding activity implicated in nucleocytoplasmic transport of adenovirus and cellular mRNAs. J Virol 1998;72:7960-7971

13. Kim WT, Seo Choi H, Min Lee H, Jang YJ, Ryu CJ. B-cell receptor-associated protein 31 regulates human embryonic stem cell adhesion, stemness, and survival via control of epithelial cell adhesion molecule. Stem Cells 2014;32:26262641

14. Kim WT, Choi HS, Hwang HJ, Jung HS, Ryu CJ. Epitope mapping of antibodies suggests the novel membrane topology of B-cell receptor associated protein 31 on the cell surface of embryonic stem cells: the novel membrane topology of BAP31. PLoS One 2015;10:e0130670

15. Choi HS, Lee HM, Jang YJ, Kim CH, Ryu CJ. Heterogeneous nuclear ribonucleoprotein $\mathrm{A} 2 / \mathrm{B} 1$ regulates the self-renewal and pluripotency of human embryonic stem cells via the control of the G1/S transition. Stem Cells 2013;31:
2647-2658

16. Hentze H, Soong PL, Wang ST, Phillips BW, Putti TC, Dunn NR. Teratoma formation by human embryonic stem cells: evaluation of essential parameters for future safety studies. Stem Cell Res 2009;2:198-210

17. Choi HS, Lee HM, Kim WT, Kim MK, Chang HJ, Lee HR, Joh JW, Kim DS, Ryu CJ. Detection of mycoplasma infection in circulating tumor cells in patients with hepatocellular carcinoma. Biochem Biophys Res Commun 2014;446:620-625

18. Choo AB, Tan HL, Ang SN, Fong WJ, Chin A, Lo J, Zheng L, Hentze H, Philp RJ, Oh SK, Yap M. Selection against undifferentiated human embryonic stem cells by a cytotoxic antibody recognizing podocalyxin-like protein-1. Stem Cells 2008;26:1454-1463

19. Watanabe K, Ueno M, Kamiya D, Nishiyama A, Matsumura M, Wataya T, Takahashi JB, Nishikawa S, Muguruma K, Sasai Y. A ROCK inhibitor permits survival of dissociated human embryonic stem cells. Nat Biotechnol 2007;25:681-686 